\title{
Characterization, Long-Range Transport and Source Identification of Carbonaceous Aerosols during Spring and Autumn Periods at a High Mountain Site in South China
}

\author{
Hong-yan Jia ${ }^{1}$, Lei Wang ${ }^{2}$, Peng-hui Li ${ }^{1, *}$, Yan Wang ${ }^{3, *}$, Li-qiong Guo ${ }^{4}$, Tao Li ${ }^{3}$, Lei Sun ${ }^{3}$, \\ You-ping Shou ${ }^{5}$, Tian-yu Mao ${ }^{5}$ and Xian-liang Yi ${ }^{6}$ \\ 1 School of Environmental Science and Safety Engineering, Tianjin University of Technology, \\ Tianjin 300384, China; jhy_cumt@163.com \\ 2 Hebei Geological Laboratory, Hebei 071051, China; wanglei8812@126.com \\ 3 School of Environmental Science and Engineering, Shandong University, Jinan 250100, China; \\ litao0201@gmail.com (T.L.); sunlei405@mail.sdu.edu.cn (L.S.) \\ 4 Department of Occupational \& Environmental Health, School of Public Health, Tianjin Medical University, \\ Tianjin 300070, China; yingqidao@163.com \\ 5 Key Laboratory of Environmental Protection Technology on Water Transport, Ministry of Transport, \\ Tianjin Research Institute for Water Transport Engineering, Tianjin 300456, China; \\ syp851228@126.com (Y.-p.S.); zyhj@vip.163.com (T.-y.M.) \\ 6 School of Food and Environment, Dalian University of Technology, Panjin 124221, China; \\ yixianliang120@hotmail.com \\ * Correspondences: lipenghui406@163.com (P.-h.L.); wy@sdu.edu.cn (Y.W.); \\ Tel.: +86-22-6021-4185 (P.-h.L.); +86-531-8836-1157 (Y.W.); Fax: +86-531-8836-1157 (Y.W.)
}

Academic Editor: Robert W. Talbot

Received: 18 August 2016; Accepted: 21 September 2016; Published: 26 September 2016

\begin{abstract}
PM}_{10}$ (particulate matter) samples were collected at Mount Lu, a high elevation mountain site in south China (August and September of 2011; and March, April and May of 2012). Eight carbonaceous fractions of particles were analyzed to characterize the possible carbonaceous emission sources. During the sampling events, daily average concentrations of $\mathrm{PM}_{10}$ at Mount $\mathrm{Lu}$ were $97.87 \mu \mathrm{g} / \mathrm{m}^{3}$ and $73.40 \mu \mathrm{g} / \mathrm{m}^{3}$ in spring and autumn, respectively. The observed mean organic carbon (OC) and element carbon (EC) concentrations during spring in $\mathrm{PM}_{10}$ were $10.58 \mu \mathrm{g} / \mathrm{m}^{3}$ and $2.58 \mu \mathrm{g} / \mathrm{m}^{3}$, respectively, and those in autumn were $6.89 \mu \mathrm{g} / \mathrm{m}^{3}$ and $2.40 \mu \mathrm{g} / \mathrm{m}^{3}$, respectively. Secondary organic carbon concentration was $4.77 \mu \mathrm{g} / \mathrm{m}^{3}$ and $2.93 \mu \mathrm{g} / \mathrm{m}^{3}$ on average, accounting for $28.0 \%$ and $31.0 \%$ of the total OC in spring and autumn, respectively. Relationships between carbonaceous species and results of principal component analysis showed that there were multiple sources contributing to the carbonaceous aerosols at the observation site. Through back trajectory analysis, it was found that air masses in autumn were mainly transported from the south of China, and these have the highest $\mathrm{OC}$ but lowest EC concentrations. Air masses in spring transported from northwest China bring $7.77 \mu \mathrm{g} / \mathrm{m}^{3} \mathrm{OC}$ and $2.28 \mu \mathrm{g} / \mathrm{m}^{3}$ EC to the site, with lower levels coming from other sites. These air mass sources were featured by the effective carbon ratio (ECR).
\end{abstract}

Keywords: organic carbon; element carbon; long-range transport; $\mathrm{PM}_{10}$; source analysis

\section{Introduction}

Carbonaceous aerosol, comprised of organic and elemental carbon (OC and EC), is ubiquitous in the Earth's atmosphere [1,2]. OC and EC in suspended particulate matter (PM) play important roles in visibility, climate and health effects [3]. EC, which is often equated with optically-derived and 
light-absorbing black carbon, is mainly emitted from anthropogenic combustion sources. There are two existing forms of particulate OC, namely primary OC (POC) and secondary OC (SOC). POC is directly emitted into the atmosphere, while SOC is formed through atmospheric oxidation of reactive organic gases and subsequent gas-to-particle conversion processes [4-6]. In urban air, second organic aerosol (SOA) accounted for $30 \%-60 \%$ of the OA; while in rural air and the free troposphere, it accounted for more than $70 \%$ of the OA [7].

In last several decades, carbonaceous aerosols from anthropogenic emissions in Asia are increasing [5,8], and China is one of the biggest emissions contributors, accounting for over $50 \%$ of the total emission of carbonaceous pollutants in Asia [2]. A few studies on carbonaceous aerosols have been conducted in developed urban areas in China [9], such as Beijing [10,11], Tianjin [5,12] and the Pearl River Delta Region (PRDR) [13,14], while observations of carbonaceous aerosols in mountain regions are very limited. Mount Lu is located at an altitude of $1165 \mathrm{~m}$ A.S.L. (above sea level) in South China. The summit of Mount Lu could perform as a special site representing the regional pollution conditions, and it is appropriate to estimate both the source of aerosols and aerosol characteristics in the free troposphere [2]. Therefore, in this study, concentrations of OC and EC in $\mathrm{PM}_{10}$ were measured in spring and autumn at Mount Lu. The objectives of this study were (1) to characterize the concentrations and temporal variations of organic carbon and element carbon in the $\mathrm{PM}_{10}$ at the high elevation, and (2) to estimate SOC concentration and examine the possible source apportionment of carbonaceous aerosols in the region.

\section{Methodology}

\subsection{Sampling}

Mount $\mathrm{Lu}$, covering an area of $300 \mathrm{~km}^{2}$, is situated to the north of Jiangxi Province. It is one of the most renowned mountains in the country. Two developed regions, namely PRDR and the Yangtze River Delta Region (YRDR), are about $700 \mathrm{~km}$ to the southwest and $400 \mathrm{~km}$ to the northeast of the mountain, respectively. The Guling town, with a population of about ten thousand, is situated on the top of Mount Lu. This mountain area is essentially free from local pollution. This is because most residents in the town work in tourism and its related services.

A total of $68 \mathrm{PM}_{10}$ samples were collected in August and September, 2011 and from March to May, 2012 at a meteorological station $\left(29^{\circ} 35^{\prime} \mathrm{N}, 115^{\circ} 59^{\prime} \mathrm{E}, 116 \mathrm{~m}\right.$ A.S.L.) established in the year of 1954 at the summit of Mount Lu (Figure 1). $\mathrm{PM}_{10}$ samples were collected on quartz fiber filters (Pall Corporation, New York, USA, pre-fired at $450{ }^{\circ} \mathrm{C}$ for $6 \mathrm{~h}$ ) by a medium volume air sampler (TH-150C, Tianhong Intelligent Instrument Plant of Wuhan, China), operating at a flow rate of $100 \mathrm{~L} / \mathrm{min}$ for $23 \mathrm{~h}$ daily (from 9 a.m. to 8 a.m.). After sampling, each sample was separately wrapped with aluminum foil and stored at $4{ }^{\circ} \mathrm{C}$ before analysis conducted within 15 days.

\subsection{Carbonaceous Species Analysis}

Carbonaceous species in collected particulate samples were analyzed with Desert Research Institute (DRI) Model 2001 (Thermal/Optical Carbon Analyzer, Atmoslytic Inc., Calabasas, CA, USA). A $0.526 \mathrm{~cm}^{2}$ punch from each sample was analyzed for eight carbon fractions according to the manufacturer's protocol (Interagency Monitoring of Protected Visual Environments (IMPROVE) thermal/optical reflectance): $140{ }^{\circ} \mathrm{C}(\mathrm{OC} 1), 280{ }^{\circ} \mathrm{C}(\mathrm{OC} 2), 480{ }^{\circ} \mathrm{C}(\mathrm{OC} 3)$, and $580{ }^{\circ} \mathrm{C}$ (OC4) in a non-oxidizing helium (He) atmosphere, and $580^{\circ} \mathrm{C}(\mathrm{EC} 1), 740{ }^{\circ} \mathrm{C}(\mathrm{EC} 2)$, and $840{ }^{\circ} \mathrm{C}$ (EC3) in an oxidizing atmosphere of $2 \%$ oxygen in a balance of helium.

The carbon that evolves at each temperature is oxidized to carbon dioxide $\left(\mathrm{CO}_{2}\right)$ and then reduced to methane $\left(\mathrm{CH}_{4}\right)$ for quantification with a flame ionization detector. As temperature increases in the inert helium, some of the organic carbon pyrolyzes to elemental carbon, resulting in darkening of the filter deposit. This darkening is monitored by reflectance of $633 \mathrm{~nm}$ light of an He-Ne laser. When oxygen is added, the original and pyrolyzed elemental carbon combusts and the reflectance increases. 
The amount of carbon measured after oxygen is added until the reflectance achieves its original value is reported as optically detected pyrolyzed carbon (OPC). The eight fractions OC1, OC2, OC3, OC4, $\mathrm{EC} 1, \mathrm{EC} 2, \mathrm{EC} 3$, and OPC are reported separately in the data sheet. The IMPROVE protocol defines OC as $\mathrm{OC} 1+\mathrm{OC} 2+\mathrm{OC} 3+\mathrm{OC} 3+\mathrm{OC} 4+\mathrm{OPC}$ and $\mathrm{EC}$ as $\mathrm{EC} 1+\mathrm{EC} 2+\mathrm{EC} 3-\mathrm{OPC}[2,5,15]$. The analyzer was calibrated daily with known quantities of $\mathrm{CH}_{4}$. The detection limit of this method is $0.01 \mu \mathrm{g}$. Blank filters were collected similar to the protocol used for samples, in order to correct carbonaceous species. In addition, the ions of $\mathrm{PM}_{10}$ samples were analyzed by Dionex IC (ionic composition)-2500 (Dionex, TX, USA).

Meteorological data for the sampling site during the sampling events were obtained from automatic weather system reports published by local meteorological station.

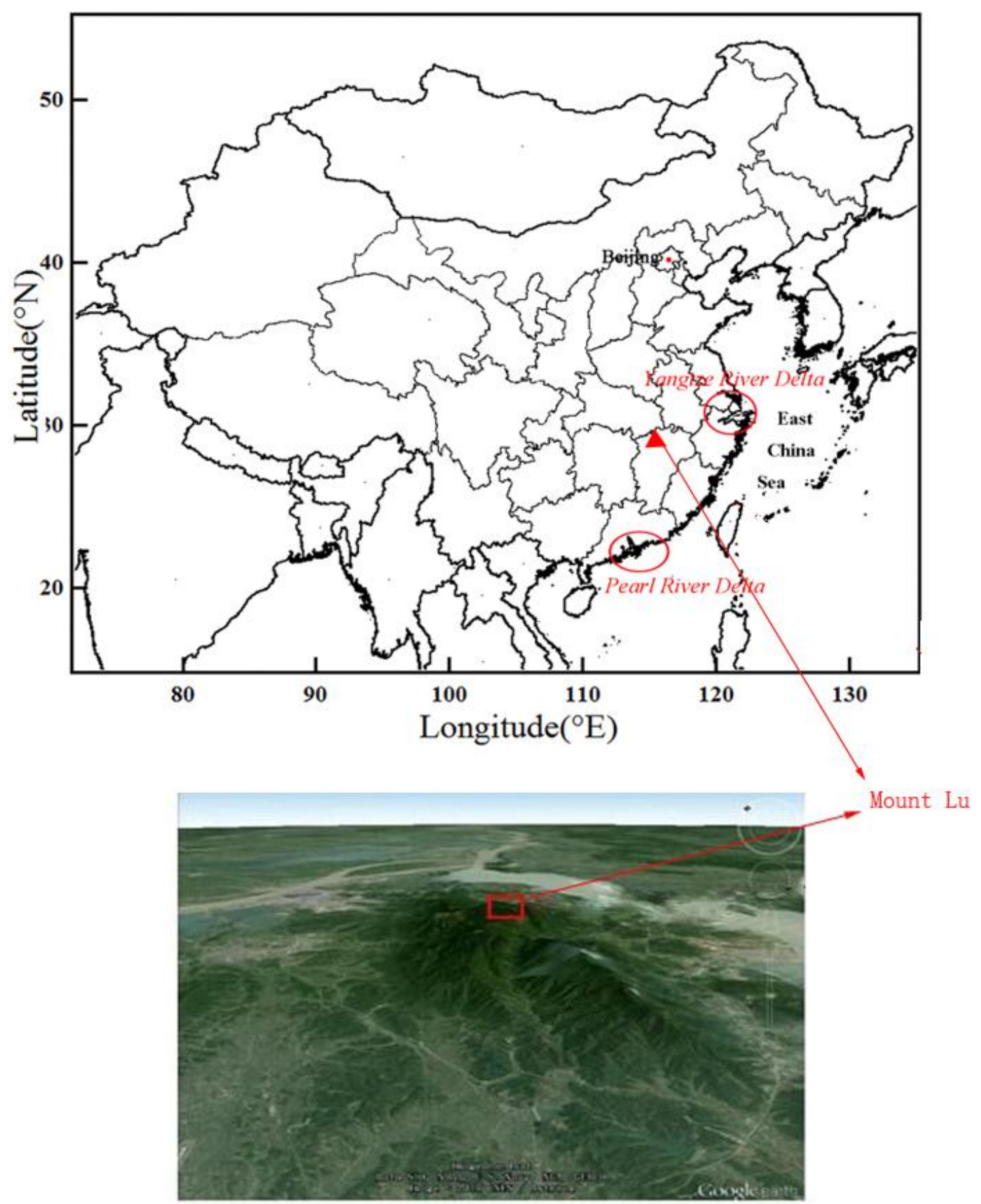

Figure 1. Map showing the location of the sampling site at Mount Lu and nearby geographical settings. 


\section{Result and Discussion}

\subsection{Temporal Variability}

Daily concentrations of $\mathrm{PM}_{10}$ at Mount Lu ranged from 33.60 to $193.74 \mu \mathrm{g} / \mathrm{m}^{3}$ and 4.55 to $231.46 \mu \mathrm{g} / \mathrm{m}^{3}$, with an average of $97.87 \mu \mathrm{g} / \mathrm{m}^{3}$ and $73.40 \mu \mathrm{g} / \mathrm{m}^{3}$ in spring and autumn, respectively (Table 1). The concentrations of carbonaceous species showed pronounced temporal variability during the study period (August-September, 2011 and March-May, 2012). The maximum-to-minimum ratios for $\mathrm{PM}_{10}$ were 145.54 and 13.45 for $\mathrm{OC}$ and $\mathrm{EC}$, respectively. The higher variability for OC concentrations may be attributed to different emission sources [15]. According to the previous studies, the average OC concentration emitted from coal combustion and biomass burning was 4.79 and $1.38 \mu \mathrm{g} / \mathrm{m}^{3}$, respectively. While the contribution of motor vehicle exhaust to OC can vary from $0.08 \mu \mathrm{g} / \mathrm{m}^{3}$ to $22.25 \mu \mathrm{g} / \mathrm{m}^{3}$ [16,17]. In this study, concentrations of $\mathrm{PM}_{10}, \mathrm{OC}$ and EC in the samples collected in spring (average temperature: $12.13^{\circ} \mathrm{C}$ ) were $1.33,1.5$ and 1.07 times as high as those in the samples collected during fall (average temperature: $19.8^{\circ} \mathrm{C}$ ), indicating higher concentrations of carbon aerosols during the colder months. This pattern is consistent with our previous findings that higher concentrations of carbon aerosols were always found in the colder months. This phenomenon might be attributed to enhanced biomass burning, gasoline fuel and typical meteorological conditions (less efficient photochemical decomposition and lower inversion height) [5].

Table 1. Statistical summary of OC (organic carbon), EC (elemental carbon) and $\mathrm{PM}_{10}$ (particulate matter) concentrations.

\begin{tabular}{|c|c|c|c|c|c|c|c|c|c|c|c|c|c|c|c|c|}
\hline \multirow{2}{*}{\multicolumn{2}{|c|}{$\begin{array}{c}\text { Sample } \\
\text { Numbers }\end{array}$}} & \multicolumn{3}{|c|}{ EC } & \multicolumn{3}{|c|}{ OC } & \multicolumn{3}{|c|}{ OC/EC } & \multicolumn{3}{|c|}{ TC (total carbon) } & \multicolumn{3}{|c|}{$\mathbf{P M}_{10}$ (particulate matter) } \\
\hline & & Ave & Min & Max & Ave & Min & Max & Ave & Min & Max & Ave & Min & Max & Ave & Min & Max \\
\hline & & 00 & BDL & & 10.58 & BDL & & 3.91 & BDL & & 0.28 & & & $\gamma$ & 33.60 & \\
\hline Autumn & n 33 & 2.40 & 0.47 & 6.32 & 6.89 & 0.22 & 32.02 & 3.27 & 0.28 & 11.21 & 0.29 & 0.98 & 35.25 & 73.40 & 4.55 & 231.46 \\
\hline
\end{tabular}

Ave: arithmetic means value; Min: the minimum value; Max: the maximum value; Spring includes March, April, and May in 2012; Autumn includes August and September in 2011; BDL: below detection limit.

Carbonaceous aerosol concentrations at Mount Lu were compared with other background sites (Table 2), and the results showed that the EC concentrations in $\mathrm{PM}_{10}$ at Mount Lu were generally higher than that reported in Kathmandu, Nepal $\left(1.5 \mu \mathrm{g} / \mathrm{m}^{3}\right)$ [18], Nagarkot, Nepal $\left(0.94 \mu \mathrm{g} / \mathrm{m}^{3}\right)$ [18], Zhuzhang, China $\left(0.34 \mu \mathrm{g} / \mathrm{m}^{3}\right)$ [19] and Shangri-La, China $\left(0.34 \mu \mathrm{g} / \mathrm{m}^{3}\right)$ [20]. In contrast, they were lower than those in Kaohsiung, Taiwan $\left(6.1 \mu \mathrm{g} / \mathrm{m}^{3}\right)$ [21] and Hangzhou, China $\left(4.06 \mu \mathrm{g} / \mathrm{m}^{3}\right)$ [22].

The OC levels decreased in the order of Hangzhou, China $\left(21.41 \mu \mathrm{g} / \mathrm{m}^{3}\right)$, Kaohsiung, Taiwan $\left(14.5 \mu \mathrm{g} / \mathrm{m}^{3}\right)$, Nagarkot, Nepal $\left(14.375 \mu \mathrm{g} / \mathrm{m}^{3}\right)$, Kathmandu, Nepal $\left(14.37 \mu \mathrm{g} / \mathrm{m}^{3}\right)$, Mount Lu, China $\left(10.58 \mu \mathrm{g} / \mathrm{m}^{3}\right)$, Zhuzhang, China $\left(3.13 \mu \mathrm{g} / \mathrm{m}^{3}\right)$, Shangri-La, China $\left(3.1 \mu \mathrm{g} / \mathrm{m}^{3}\right)$ and Puy de Dome, France $\left(2.4 \mu \mathrm{g} / \mathrm{m}^{3}\right)$. Although the analytical methods of carbonaceous aerosols in these studies are different, the results could still provide an overall picture to compare carbonaceous aerosols distributions in different regions.

The origin of carbonaceous aerosols can be reflected by the relationship between OC and EC [23]. In this study, OC and EC had similar temporal variations (Figures 2 and 3) and were well related to each other (Figures 4 and 5), indicating common emission sources and similar atmospheric processes shared by OC and EC during the observation period. It has been previously reported that an OC/EC ratio exceeding 2 or 2.2 indicated the presence of secondary organic aerosol [2,24]. In this study, the average OC/EC ratios in $\mathrm{PM}_{10}$ at Mount Lu were 3.91 and 3.27 in spring and autumn, respectively (Table 1), and these values were comparable to the OC/EC ratio in other sites listed in Table 2 and higher than 2.2, suggesting that SOC may have contributed largely to the carbonaceous aerosols at Mount $\mathrm{Lu}$. The OC/EC ratios in this study were also higher than those observed in urban areas in China including Beijing (a ratio of 2.9), Shanghai (a ratio of 2.5) and PRDR (a ratio of 2.4) [13,25]. 
Table 2. Comparisons of EC (elemental carbon) and OC (organic carbon) concentrations, and OC/EC ratios among various background sites around the world.

\begin{tabular}{|c|c|c|c|c|c|c|c|}
\hline Location & Size & Time Period & $\begin{array}{c}\text { EC } \\
\left(\mu \mathrm{g} / \mathrm{m}^{3}\right)\end{array}$ & $\underset{\left(\mu \mathrm{g} / \mathrm{m}^{3}\right)}{\mathrm{OC}}$ & OC/EC & Analysis Method & Reference \\
\hline Mount Lu, China & $\mathrm{PM}_{10}$ & August-September 2011 & 2.58 & 10.58 & 3.91 & TOR & this study \\
\hline Shangri-La,China & $\mathrm{PM}_{10}$ & 2006 & 0.34 & 3.1 & 11.9 & & {$[20]$} \\
\hline Zhuzhang, China & $\mathrm{PM}_{10}$ & July 2004-March 2005 & 0.34 & 3.13 & 11.9 & TOR & [19] \\
\hline Kathmandu, Nepal & $\mathrm{PM}_{10}$ & February-May 2000 & 1.5 & 14.37 & & TOT & [18] \\
\hline Nagarkot, Nepal & $\mathrm{PM}_{10}$ & February-May 2000 & 0.94 & 14.375 & & TOT & {$[18]$} \\
\hline Kaohsiung, Taiwan & $\mathrm{PM}_{10}$ & November 1998-April 1999 & 6.1 & 14.5 & 2.4 & Elemental analyzer & [21] \\
\hline Hangzhou, China & $\mathrm{PM}_{10}$ & September 2001-August 2002 & 4.06 & 21.41 & 5.27 & TOT & [22] \\
\hline
\end{tabular}

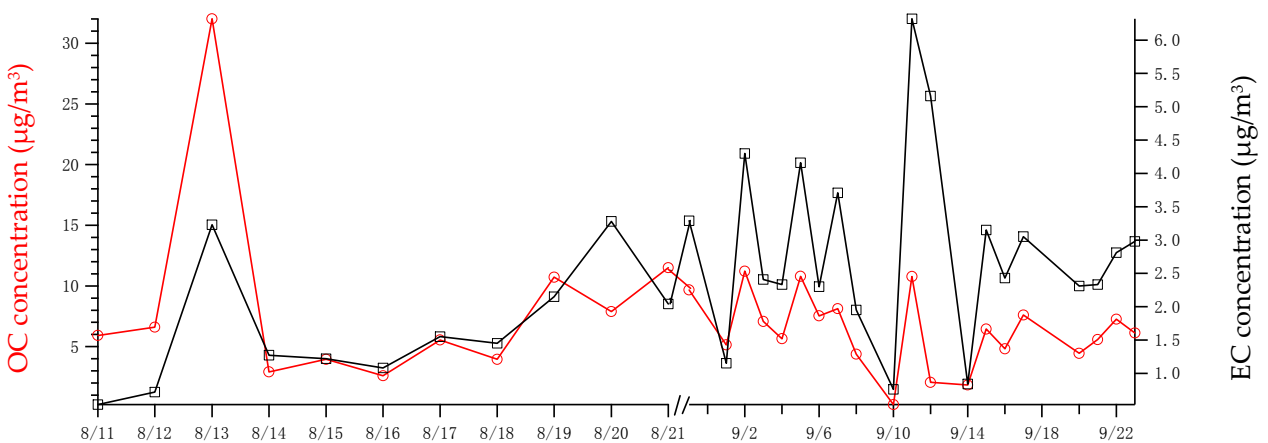

Figure 2. Temporal variations of OC (organic carbon) and EC (elemental carbon) concentrations in autumn.

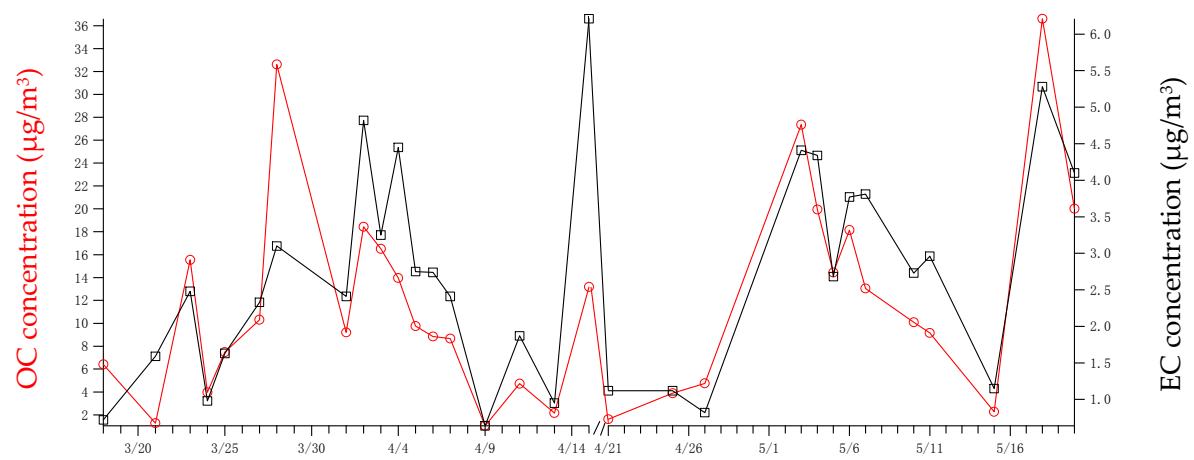

Figure 3. Temporal variations of OC and EC concentrations in spring.

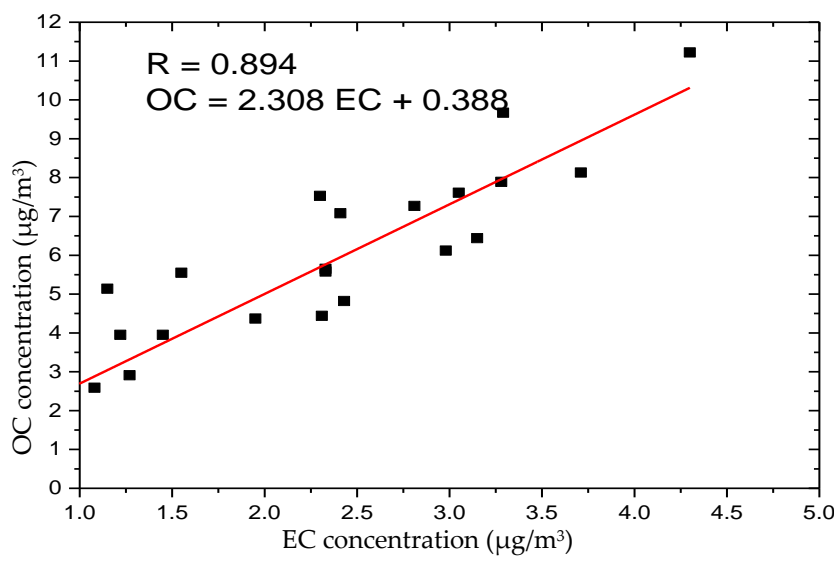

Figure 4. Scatter plot between OC and EC concentrations in autumn. 


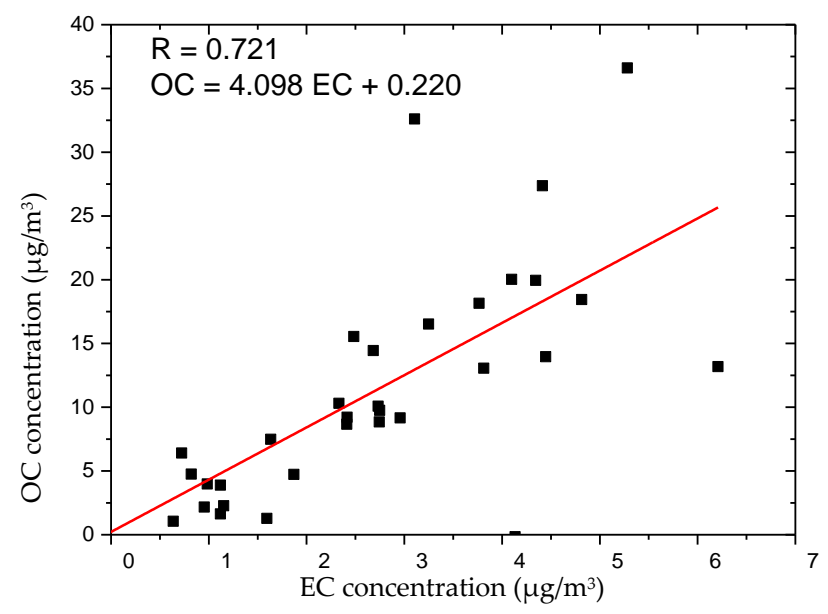

Figure 5. Scatter plot between OC and EC concentrations in spring.

\subsection{Estimation of SOC Concentrations}

EC is relatively inert regarding its chemical reactions in atmosphere, and it is solely derived from primary emissions. Unlike EC, OC can be derived from both primary emissions and the chemical reactions occurring between gaseous organic precursor species and by the oxidation of volatile organic compounds [8]. The direct measurement of SOC is unlikely to be carried out because they are derived from not only the various physical processes but also the chemical transformation processes. The EC-tracer method has been applied to estimate different fractions of SOC for various environments, such as rural, semi-urban and urban environments to evaluate the mass concentrations of SOC $[23,27,28]$, and it is therefore adopted in the present study. The equation is as follows:

$$
O C_{s e c}=O C_{t o t}-E C \times(O C / E C)_{p r i}
$$

where $\mathrm{OC}_{\mathrm{sec}}$ is the $\mathrm{SOC}$; $\mathrm{OC}_{\text {tot }}$ is the total organic carbon; and $(\mathrm{OC} / \mathrm{EC})_{\text {pri }}$ is the primary ratio. The primary OC/EC ratios can be affected by many factors including temporal fluctuations, fluctuations in emissions, meteorology conditions, and thus the ratios vary among different sources. Therefore, the determination of the primary OC/EC values is crucial. In previous studies, the ratio of OC/EC in the lowest $5 \%-10 \%$ or below the threshold of 2.9 from the least-squares regression analysis was applied [29-31]. In this study, the regression of the selected data suggested a primary OC/EC ratio of 2.06 and 3.08 in autumn and spring, respectively, which was comparable with the ratio $(\mathrm{OC} / \mathrm{EC}=2.19)$ at Mount Tai in northern China [32]. The estimated SOC concentrations varied from 0.10 to $25.38 \mu \mathrm{g} / \mathrm{m}^{3}$, with an average of $2.93 \mu \mathrm{g} / \mathrm{m}^{3}$ in autumn and from 0.11 to $22.11 \mu \mathrm{g} / \mathrm{m}^{3}$, with an average of $4.77 \mu \mathrm{g} / \mathrm{m}^{3}$ in spring. The average proportion of SOC to the total OC was $31 \%$ and $28 \%$ in the autumn and spring, respectively. Compared with SOC proportion in $\mathrm{PM}_{2.5}$ samples $(45.0 \%)$ in the same area, the average proportion for $\mathrm{PM}_{10}$ in autumn was lower [2], indicating that SOC mainly enriched in fine particles.

As an important characteristic of particles, aerosol acidity can alter the uptake of precursors and the partitioning of volatile and semi-volatile compounds between the particle and gas phases, thereby affecting aerosol phase relations [2]. In general, $\left[\mathrm{H}^{+}\right]_{\text {strong }}$ (calculated as $2 \times \mathrm{SO}_{4}{ }^{2-}+\mathrm{NO}_{3}{ }^{-}-\mathrm{NH}_{4}{ }^{+}$) was suggested to be an indicator of aerosol acidity. For $\mathrm{PM}_{2.5}$ samples at Mount Lu in autumn, the average concentration of $\left[\mathrm{H}^{+}\right]_{\text {strong }}$ was $52.7 \mathrm{nmol} / \mathrm{m}^{3}$, indicating that a general acidic state of the fine particles at Mount Lu. Furthermore, a good correlation between $\left[\mathrm{H}^{+}\right]_{\text {strong }}$ and SOC suggested a dominant role of aerosol acidity in the formation of SOAs [2].

In this study, the data obtained during the special climate events like cloud/fog events and dust storms were excluded in the analysis of acidity. The concentrations of $\left[\mathrm{H}^{+}\right]_{\text {strong }}$ ranged from 0.10 to $29.21 \mathrm{nmol} / \mathrm{m}^{3}$ (with the mean of $4.57 \mathrm{nmol} / \mathrm{m}^{3}$ ) in autumn and from 0.01 to $53.35 \mathrm{nmol} / \mathrm{m}^{3}$ 
(with the mean value of $5.05 \mathrm{nmol} / \mathrm{m}^{3}$ ) in spring. These values were 10 times lower than those in $\mathrm{PM}_{2.5}$ samples, suggesting that the acidic material was mainly associated with fine particles. In addition, the correlation between $\mathrm{SOC}$ and $\left[\mathrm{H}^{+}\right]_{\text {strong }}$ in this study was not as strong as that for $\mathrm{PM}_{2.5}$, indicating that reactions catalyzed by heterogeneous acid may have contributed to the formation of SOA in fine particles rather than coarse particles [8].

\subsection{Source Apportionment of Carbonaceous Species}

The ratio of EC/TC can differentiate the dominant contributors among fossil fuel burning and biomass burning. An EC/TC ratio between 0.1 and 0.2 indicates the source of carbonaceous species contributed by biomass burning, while a higher ratio $(\sim 0.5)$ suggests the source coming from fossil fuel combustion [33-36]. In this study, the average EC/TC ratios of $\mathrm{PM}_{10}$ were 0.18 and 0.25 in spring and autumn at Mount Lu, respectively, indicating that biomass burning was the main source of carbonaceous aerosols at the observation site. Similarly, in previous studies, biomass burning in open fire and residential consumption was suggested as one of the most important carbonaceous emission sources in China [2,12].

However, because of great variations in emission patterns in different countries, these ratios may not accurately reflect emission characteristics. Therefore, principal component analysis (PCA) was conducted for eight carbon fractions to further characterize the possible emission sources of carbonaceous aerosols at the observation site.

Results of PCA for samples collected in autumn and spring are summarized in Tables 3 and 4. For $\mathrm{PM}_{10}$ autumn samples, and two factors accounted for $75.75 \%$ of the total variance in the data. Factor 1, explaining $46.12 \%$ of the variance, presented high loading for OC2, OC3, OC4, EC1 and OPC. Among these fractions, OC2 and OPC originated from coal combustion, and OC3, OC4 and EC1 represented gasoline-motor-vehicle exhaust. This factor appears to represent gasoline motor vehicle exhaust and coal combustion [37]. Factor 2, which explained $29.63 \%$ of the variance, showed high loadings for OC1, EC2 and EC3. The high loading of OC1 in factor 2 reflected the contribution of biomass burning, and EC2 and EC3 were enriched in diesel-vehicle exhaust. Thus, factor 2 represented diesel vehicle exhaust and biomass burning.

In spring, three factors accounted for $87.07 \%$ of the total variance. Among these factors, factor 1 explained $47.51 \%$ of the variance, and it had high loading for OC2, OC3, OC4, EC1 and OPC. Similar to the fall results, Factor 1 in spring represents gasoline motor vehicle exhaust and coal combustion. Factor 2, which explained $20.48 \%$ of the variance, showed high loadings for EC2, EC3, from which the diesel-vehicle exhaust sources could be inferred [5]. As for factor 3, the high loading of OC1 reflected the main contribution from biomass burning.

Table 3. PCA (principal component analysis) analysis of carbonaceous species for $\mathrm{PM}_{10}$ (particulate matter) autumn samples.

\begin{tabular}{ccc}
\hline Species & Factor1 & Factor2 \\
\hline OC1 & 0.643 & 0.824 \\
OC2 & 0.893 & \\
OC3 & 0.840 & 0.802 \\
OC4 & 0.852 & 0.926 \\
EC1 & & $29.63 \%$ \\
EC2 & 0.897 & $75.75 \%$ \\
EC3 & $46.12 \%$ & $46.12 \%$ \\
OPC & Gasoline motor vehicle exhau + coal combustion & Diesel vehicle exhaust + biomass burning \\
Percentage of the variance &
\end{tabular}


Table 4. PCA (principal component analysis) analysis of carbonaceous species for $\mathrm{PM}_{10}$ (particulate matter) spring samples.

\begin{tabular}{cccc}
\hline Species & Factor1 & Factor2 & Factor3 \\
\hline OC1 (organic carbon) & & & 0.924 \\
OC2 & 0.602 & & \\
OC3 & 0.899 & & \\
OC4 & 0.802 & & \\
EC1 (elemental carbon) & 0.925 & 0.674 & \\
EC2 & & 0.867 & $16.08 \%$ \\
EC3 & 0.899 & & $84.07 \%$ \\
OPC & $47.51 \%$ & $20.48 \%$ & $67.98 \%$ \\
Percentage of the & $47.51 \%$ & biomass burning \\
variance & gasoline motor vehicle exhaust + coal combustion & diesel vehicle exhaust & \\
Cumulative & & &
\end{tabular}

\subsection{Long-Range Transport of Carbonaceous Aerosol}

To better elucidate the origin and transport patterns for air mass samples, $72 \mathrm{~h}$ back trajectory was analyzed by the Hybrid Single Particle Lagrangian Integrated Trajectory (HYSPLIT) model with FNL (final analysis data) meteorological datasets at a height of $1165 \mathrm{~m}$ A.S.L. (above sea level) (Figures 6 and 7). Owing to the occurrence of scavenging in fog or cloud conditions, the trajectory analysis did not include the samples collected during fog or cloud periods.

In autumn, all the air masses can be classified into three categories, namely N/NE-air (north/northeast of China) masses, S-air (south of China) masses and E-air (east of China) masses. Among the three trajectory categories, the N/NE-air masses that originate from continental areas in northern and northeastern China crossed the Beijing-Tianjin-Hebei region and the Shandong province and finally reached the station; the S-air masses came from coastal areas in southern China and then crossed Guangdong before finally reaching the station; the E-air masses originated from coastal areas in the east part of China and then traveled to the station across Zhejiang and Fujian provinces. It is noteworthy that this paper has omitted the air masses associated with trajectory that passed over two regions.

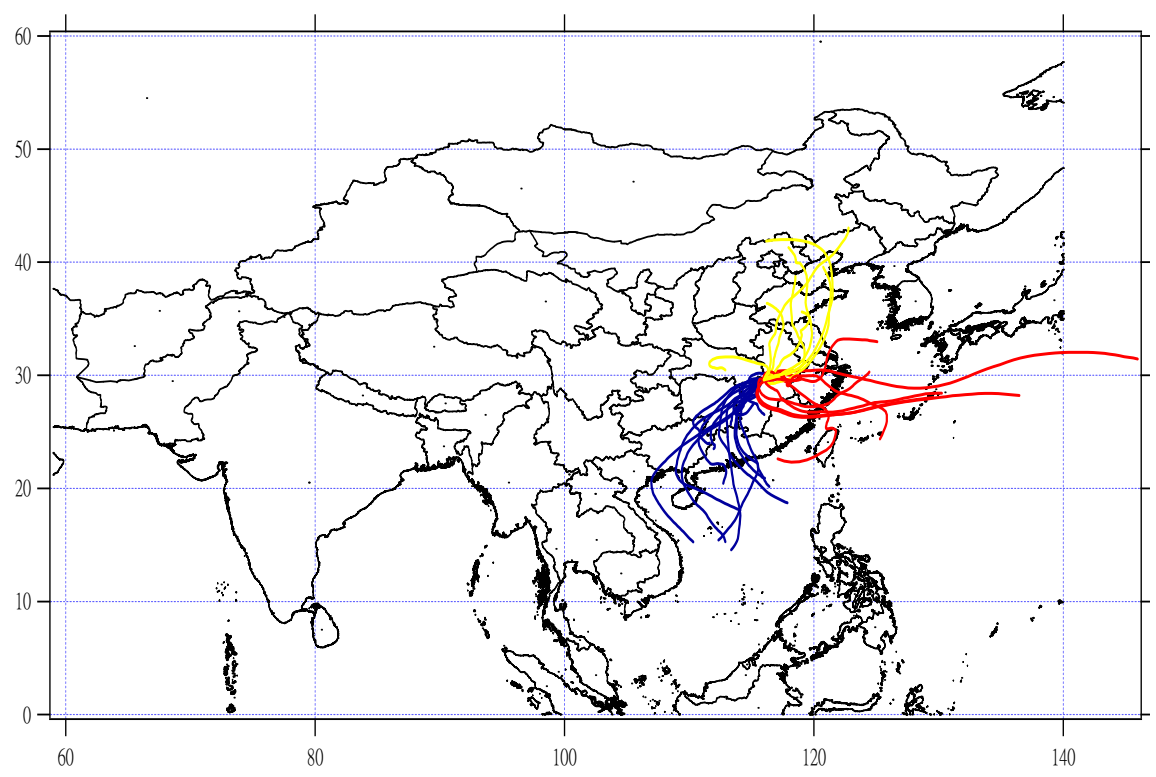

Figure 6. Seventy-two hour backward trajectories for $\mathrm{PM}_{10}$ (particulate matter) samples at Mount Lu in autumn. 


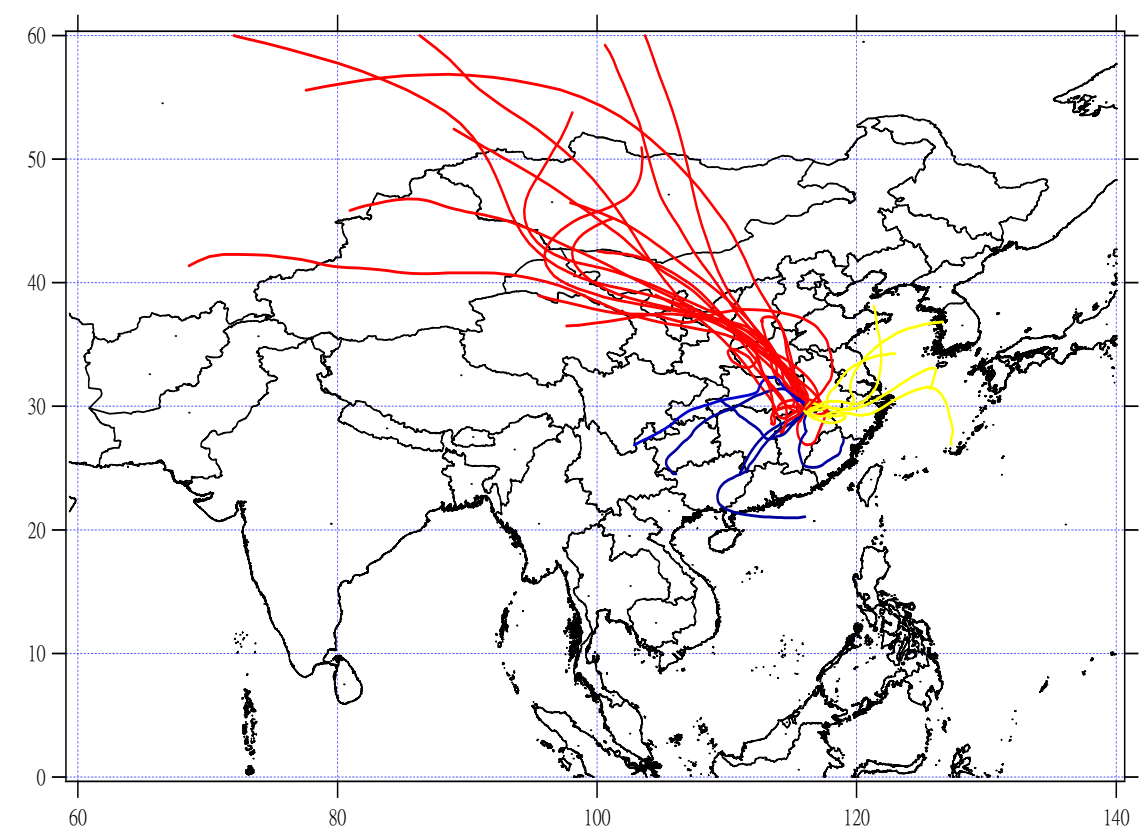

Figure 7. Seventy-two hour backward trajectories for $\mathrm{PM}_{10}$ samples at Mount $\mathrm{Lu}$ in spring.

As can be seen from Table 5, S occupied the dominant position, accounting for $43.75 \%$ of the total, while E-air masses and N/NE-air masses happened less frequently, accounting for $31.25 \%$ and $25 \%$, respectively. Compared with E-air masses and S-air masses whose $\mathrm{PM}_{10}$ concentrations were $70.52 \mu \mathrm{g} / \mathrm{m}^{3}$ and $66.58 \mu \mathrm{g} / \mathrm{m}^{3}$, respectively, N/NE-air masses had a relatively higher $\mathrm{PM}_{10}$ concentration of $92.33 \mu \mathrm{g} / \mathrm{m}^{3}$, due to the influence of dust storm events in this region. In addition, the sequence of $\mathrm{OC}$ concentrations among the three categories in descending order was S-air masses $\left(8.01 \mu \mathrm{g} / \mathrm{m}^{3}\right)>\mathrm{N} / \mathrm{NE}$-air masses $\left(6.81 \mu \mathrm{g} / \mathrm{m}^{3}\right)>$ E-air masses $\left(6.11 \mu \mathrm{g} / \mathrm{m}^{3}\right)$, and the sequence of EC concentrations in descending order was E-air masses $\left(3.01 \mu \mathrm{g} / \mathrm{m}^{3}\right)>\mathrm{N} / \mathrm{NE}$-air masses $\left(2.70 \mu \mathrm{g} / \mathrm{m}^{3}\right)$ $>$ S-air masses $\left(1.99 \mu \mathrm{g} / \mathrm{m}^{3}\right)$. The fact beyond expectation is that $\mathrm{S}$-air masses had the highest OC concentration, which was an average of $8.01 \mu \mathrm{g} / \mathrm{m}^{3}$. As they always came from the sea and were relatively clean, their EC concentration was the lowest. However, compared with the YRDR and northern China, the rapidly developing PRDR situated in the air mass pathway owns a different industrial structure, and the famous ozone and $\mathrm{NO}_{\mathrm{X}}$ pollution there could favor the formation of SOA $[2,38]$, and the highest SOC concentration was found in the S-air masses category.

Table 5. Occurrence percentage of different air mass trajectories, mean concentrations of $\mathrm{PM}_{10}$ (particulate matter), OC (organic carbon), EC (elemental carbon) and SOC (secondary organic carbon) for each trajectory at Mount Lu during autumn.

\begin{tabular}{cccccccccc}
\hline \multirow{2}{*}{$\begin{array}{c}\text { Air Mass } \\
\text { Trajectory }\end{array}$} & \multirow{2}{*}{ Occurrence } & \multicolumn{2}{c}{ Mean Concentration } & \multirow{2}{*}{ OC/EC } & \multirow{2}{*}{ OC/PM } & \multirow{2}{*}{ EC/PM } & \multirow{2}{*}{ SOC } & \multirow{2}{*}{ SOC/OC } \\
\hline S & & & & & \\
PM $_{\mathbf{1 0}}$ & OC & EC & OC) & & & & & & \\
E & $43.75 \%$ & 66.58 & 8.01 & 1.99 & 4.48 & $16.97 \%$ & $7.39 \%$ & 4.22 & $37.46 \%$ \\
N $/ \mathrm{NE}$ & $31.25 \%$ & 70.52 & 6.11 & 3.01 & 2.21 & $9.43 \%$ & $4.29 \%$ & 1.89 & $26.47 \%$ \\
\hline
\end{tabular}

Figure 6 shows the derived three trajectory clusters in the spring. The three clusters were classified according to directions as south of China (S), Northwest China (NW), and coastal areas in the east of China (E). Among the three identified trajectory clusters, NW took the dominant position, accounting for $62.5 \%$ of the total, while S and E happened less frequently, accounting for $18.75 \%$ and $18.75 \%$, respectively. The summary of statistical analysis for carbonaceous concentrations of each transport cluster is listed in Table 6. Carbonaceous areole concentration sequences of the three clusters in 
descending order were E (OC: $20.22 \mu \mathrm{g} / \mathrm{m}^{3}$, EC: $3.92 \mu \mathrm{g} / \mathrm{m}^{3}$ ) $>$ S (OC: $13.98 \mu \mathrm{g} / \mathrm{m}^{3}, \mathrm{EC}: 2.67 \mu \mathrm{g} / \mathrm{m}^{3}$ ) $>$ NW (OC: $7.77 \mu \mathrm{g} / \mathrm{m}^{3}, \mathrm{EC}: 2.28 \mu \mathrm{g} / \mathrm{m}^{3}$ ). OC $/ \mathrm{EC}$ ratio sequences of the three clusters in descending order were $\mathrm{E}$ (4.89) $>\mathrm{S}$ (4.39) $>\mathrm{NW}$ (3.77) (Table 3). The air masses originating from relatively clean northwest areas [8] were linked to lowest OC and EC concentrations, which were 7.77 and $2.28 \mu \mathrm{g} / \mathrm{m}^{3}$, respectively.

Table 6. Occurrence percentage of different air mass trajectories, mean concentrations of $\mathrm{PM}_{10}, \mathrm{OC}, \mathrm{EC}$ and SOC for each trajectory at Mount Lu during spring.

\begin{tabular}{cccccccccc}
\hline \multirow{2}{*}{$\begin{array}{c}\text { Air mass } \\
\text { trajectory }\end{array}$} & \multirow{2}{*}{$\begin{array}{c}\text { Occurrence } \\
\text { Percentage (\%) }\end{array}$} & \multicolumn{2}{c}{ Mean Concentration } & \multirow{2}{*}{ OC/EC } & \multirow{2}{*}{ OC/PM } & \multirow{2}{*}{ EC/PM } & \multirow{2}{*}{ SOC } & \multirow{2}{*}{ SOC/OC } \\
\hline SM & & OC & EC & OC & & & & & \\
\hline E & $18.75 \%$ & 90.18 & 13.98 & 2.67 & 4.39 & $13.86 \%$ & $2.84 \%$ & 8.15 & $26.95 \%$ \\
NW & $18.75 \%$ & 101.54 & 20.22 & 3.92 & 4.89 & $22.84 \%$ & $4.47 \%$ & 8.55 & $32.29 \%$ \\
& $62.5 \%$ & 98.53 & 7.77 & 2.28 & 3.77 & $7.53 \%$ & $2.42 \%$ & 2.19 & $24.94 \%$ \\
\hline
\end{tabular}

Since the chemical and optical properties of OC and EC were different, their influence on the atmosphere was different. Solar radiation can be scattered by $O C$ and directly absorbed by EC. Meanwhile, following $\mathrm{CO}_{2}$, EC acted as the second most important component causing global warming [24]. Effective carbon ratio (ECR, calculated as SOC/ (POC + EC)) was proposed by Safai, Raju [6], and it can be applied to assess the influence of carbonaceous aerosols on climate. Higher ECR value indicates lower EC and POC concentrations, which may result in a decreasing level of atmospheric warming effect. According to the study results, the ECR value of the N/NE-air masses (an average of 0.210) was much lower than that of the S-air masses (an average of 0.855) and similar to that of the E-air masses (an average of 0.289 ) in autumn. In spring, the ECR value of the S-air masses (an average of 0.579) was a little higher than that of the E-air masses (an average of 0.338) and NW-air masses (an average of 0.432) (Figures 8 and 9).

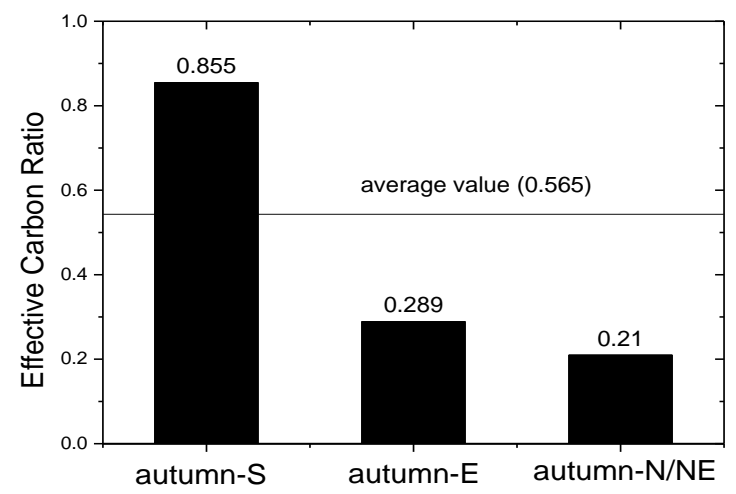

Figure 8. Effective carbon ratio (ECR) values for different air mass trajectories in autumn.

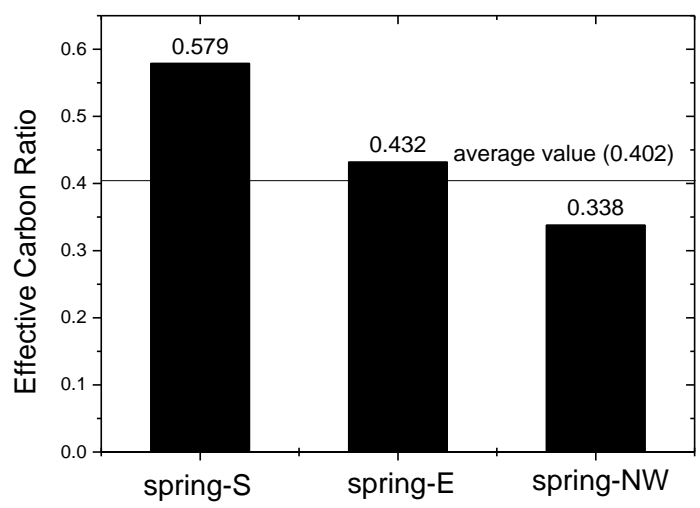

Figure 9. Effective carbon ratio (ECR) values for different air mass trajectories in spring. 


\section{Conclusions}

$\mathrm{PM}_{10}$ samples were collected at a high elevation mountain site during August-September, 2011 and March-May, 2012 in south China. The detected average concentrations of OC and EC were 6.89, $2.40 \mu \mathrm{g} / \mathrm{m}^{3}$ and $10.58,2.58 \mu \mathrm{g} / \mathrm{m}^{3}$ in spring and autumn, respectively. SOC accounted for $31.0 \%$ of the total OC in autumn and $28.0 \%$ of the total OC in spring. The correlation between SOC and $\left[\mathrm{H}^{+}\right]_{\text {strong }}$ in $\mathrm{PM}_{10}$ was not as strong as that in $\mathrm{PM}_{2.5}$, indicating that reactions catalyzed by heterogeneous acid may have contributed to SOA formation in fine particles. Results of PCA analysis suggested the carbonaceous aerosols at Mount Lu may have been contributed by multiple sources. During the study period, air masses that originated from southern China happened most frequently in autumn, and northwest China occurred most frequently in spring. The highest OC concentration and lowest EC concentration were found in the category of $S$ during autumn and the lowest $\mathrm{OC}$ and EC concentration were related with the air mass from the NW cluster during spring.

Acknowledgments: We acknowledge the Mount Lu Meteorological Station for their support in the field study and for providing meteorological data. We appreciate considerable assistance from Ya-qin Ji and Xin-feng Wang in this study. Financial support was provided by the National Natural Science Foundation of China (21177073, $41475115,41601548,81602827)$, and the Tianjin Research Program of Application Foundation and Advanced Technology (15JCQNJC08400).

Author Contributions: Peng-hui Li and Yan Wang conceived and designed the experiments; Hong-yan Jia, Peng-hui Li, Tao Li, Lei Sun, You-ping Shou and Tian-yu Mao performed the experiments; Li-qiong Guo and Hong-yan Jia analyzed the data; Xian-liang Yi and Lei Wang contributed reagents/materials/analysis tools; and Hongyan Jia wrote the paper.

Conflicts of Interest: The authors declare no conflict of interest.

\section{References}

1. Srinivas, B.; Sarin, M. PM 2.5 , EC and OC in atmospheric outflow from the Indo-Gangetic Plain: Temporal variability and aerosol organic carbon-to-organic mass conversion factor. Sci. Total. Environ. 2014, 487, 196-205. [CrossRef] [PubMed]

2. Li, P.H.; Wang, Y.; Li, T.; Sun, L.; Yi, X.; Guo, L.Q.; Su, R.H. Characterization of carbonaceous aerosols at Mount Lu in South China: Implication for secondary organic carbon formation and long-range transport. Environ. Sci. Pollut. R. 2015, 22, 14189-14199. [CrossRef] [PubMed]

3. Wang, X.; Jing, H.; Dhungel, B.; Wang, W.N.; Kumfer, B.M.; Axelbaum, R.L.; Biswas, P. Characterization of organic and black carbon aerosol formation during coal combustion: An experimental study in a $1 \mathrm{MW}$ pilot scale coal combustor. Fuel 2016, 180, 653-658. [CrossRef]

4. Vignati, E.; Karl, M.; Krol, M.; Wilson, J.; Stier, P.; Cavalli, F. Sources of uncertainties in modelling black carbon at the global scale. Atmos. Chem. Phy. 2010, 10, 2595-2611. [CrossRef]

5. Li, P.; Han, B.; Huo, J.; Lu, B.; Ding, X.; Chen, L.; Kong, S.F.; Bai, Z.P.; Wang, B. Characterization, meteorological influences and source identification of carbonaceous aerosols during the autumn-winter period in Tianjin, China. Aerosol Air Qual. Res. 2012, 12, 283-294. [CrossRef]

6. Safai, P.D.; Raju, M.P.; Rao, P.S.P.; Pandithurai, G. Characterization of carbonaceous aerosols over the urban tropical location and a new approach to evaluate their climatic importance. Atmos. Environ. 2014, 92, 493-500. [CrossRef]

7. Volkamer, R.; Ziemann, P.; Molina, M. Secondary organic aerosol formation from acetylene (C 2 H 2): Seed effect on SOA yields due to organic photochemistry in the aerosol aqueous phase. Atmos. Chem. Phys. 2009, 9, 1907-1928. [CrossRef]

8. Zhou, S.; Wang, Z.; Gao, R.; Xue, L.; Yuan, C.; Wang, T.; Gao, X.; Wang, X.; Nie, W.; Xu, Z.; et al. Formation of secondary organic carbon and long-range transport of carbonaceous aerosols at Mount Heng in South China. Atmos. Environ. 2012, 63, 203-212. [CrossRef]

9. Yang, F.; Tan, J.; Zhao, Q.; Du, Z.; He, K.; Ma, Y.; Duan, F.; Chen, G. Characteristics of PM 2.5 speciation in representative megacities and across China. Atmos. Chem. Phys. 2011, 11, 5207-5219. [CrossRef] 
10. Chen, Y.; Schleicher, N.; Cen, K.; Liu, X.; Yu, Y.; Zibat, V.; Dietze, V.; Fricker, M.; Kaminski, U.; Chen, Y.; et al. Evaluation of impact factors on $\mathrm{PM}_{2.5}$ based on long-term chemical components analyses in the megacity Beijing, China. Chemosphere 2016, 155, 234-242. [CrossRef] [PubMed]

11. Zhang, Y.; Huang, W.; Cai, T.; Fang, D.; Wang, Y.; Song, J.; Hu, M.; Zhang, Y. Concentrations and chemical compositions of fine particles $\left(\mathrm{PM}_{2.5}\right)$ during haze and non-haze days in Beijing. Atmos. Res. 2016, 174, 62-69. [CrossRef]

12. Gu, J.; Bai, Z.; Liu, A.; Wu, L.; Xie, Y.; Li, W.; Dong, H.; Zhang, X. Characterization of atmospheric organic carbon and element carbon of $\mathrm{PM}_{2.5}$ and $\mathrm{PM}_{10}$ at Tianjin, China. Aerosol Air Qual. Res. 2010, 10, 167-176. [CrossRef]

13. Cao, J.; Lee, S.; Ho, K.; Zhang, X.; Zou, S.; Fung, K.; Chow, J.C.; Watson, J.G. Characteristics of carbonaceous aerosol in Pearl River Delta Region, China during 2001 winter period. Atmos. Environ. 2003, 37, 1451-1460. [CrossRef]

14. Cao, J.J.; Lee, S.C.; Ho, K.F.; Zou, S.C.; Fung, K.; Li, Y.; Watson, J.G.; Chow, J.C. Spatial and seasonal variations of atmospheric organic carbon and elemental carbon in Pearl River Delta Region, China. Atmos. Environ. 2004, 38, 4447-4456. [CrossRef]

15. Cao, J.; Wu, F.; Chow, J.; Lee, S.; Li, Y.; Chen, S.; An, Z.; Fung, K.; Watson, J.; Zhu, C. Characterization and source apportionment of atmospheric organic and elemental carbon during fall and winter of 2003 in $\mathrm{Xi}^{\prime}$ an, China. Atmos. Chem. Phy. 2005, 5, 3127-3137. [CrossRef]

16. Watson, J.G.; Chow, J.C.; Houck, J.E. PM $\mathrm{PM}_{2.5}$ chemical source profiles for vehicle exhaust, vegetative burning, geological material, and coal burning in Northwestern Colorado during 1995. Chemosphere 2001, 43, 1141-1151. [CrossRef]

17. Saarikoski, S.; Timonen, H.; Saarnio, K.; Aurela, M.; Jarvi, L.; Keronen, P.; Kerminen, V.M.; Hillamo, R. Sources of organic carbon in fine particulate matter in northern European urban air. Atmos. Chem. Phys. 2008, 8, 6281-6295. [CrossRef]

18. Carrico, C.M.; Bergin, M.H.; Shrestha, A.B.; Dibb, J.E.; Gomes, L.; Harris, J.M. The importance of carbon and mineral dust to seasonal aerosol properties in the Nepal Himalaya. Atmos. Environ. 2003, 37, 2811-2824. [CrossRef]

19. Qu, W.J.; Zhang, X.Y.; Arimoto, R.; Wang, Y.Q.; Wang, D.; Sheng, L.F.; Fu, G. Aerosol background at two remote CAWNET sites in western China. Sci. Total Environ. 2009, 407, 3518-3529. [CrossRef] [PubMed]

20. Zhang, X.; Wang, Y.; Zhang, X.; Guo, W.; Gong, S. Carbonaceous aerosol composition over various regions of China during 2006. J. Geophys. Res. 2008, 113. [CrossRef]

21. Lin, J.J.; Tai, H.S. Concentrations and distributions of carbonaceous species in ambient particles in Kaohsiung City, Taiwan. Atmos. Environ. 2001, 35, 2627-2636. [CrossRef]

22. Cao, J.; Shen, Z.; Chow, J.C.; Qi, G.; Watson, J.G. Seasonal variations and sources of mass and chemical composition for $\mathrm{PM}_{10}$ aerosol in Hangzhou, China. Particuology 2009, 7, 161-168. [CrossRef]

23. Turpin, B.J.; Huntzicker, J.J. Identification of secondary organic aerosol episodes and quantitation of primary and secondary organic aerosol concentrations during SCAQS. Atmos. Environ. 1995, 29, 3527-3544. [CrossRef]

24. Pipal, A.S.; Tiwari, S.; Satsangi, P.G.; Taneja, A.; Bisht, D.S.; Srivastava, A.K.; Srivastava, M.K. Sources and characteristics of carbonaceous aerosols at Agra "World heritage site" and Delhi "capital city of India". Environ. Sci. Pollut. R. 2014, 21, 8678-8691. [CrossRef] [PubMed]

25. Yang, F.; He, K.; Ye, B.; Chen, X.; Cha, L.; Cadle, S.; Chan, T.; Mulawa, P. One-year record of organic and elemental carbon in fine particles in downtown Beijing and Shanghai. Atmos. Chem. Phys. 2005, 5, 1449-1457. [CrossRef]

26. Pio, C.; Legrand, M.; Oliveira, T.; Afonso, J.; Santos, C.; Caseiro, A.; Fialho, P.; Barata, F.; Puxbaum, H.; Sanchez-Ochoa, A. Climatology of aerosol composition (organic versus inorganic) at nonurban sites on a west-east transect across Europe. J. Geophys. Res. 2007, 112. [CrossRef]

27. Ram, K.; Sarin, M.; Tripathi, S. A 1 year record of carbonaceous aerosols from an urban site in the Indo-Gangetic Plain: Characterization, sources, and temporal variability. J. Geophys. Res. 2010, 115. [CrossRef]

28. Cabada, J.C.; Pandis, S.N.; Subramanian, R.; Robinson, A.L.; Polidori, A.; Turpin, B. Estimating the secondary organic aerosol contribution to $\mathrm{PM}_{2.5}$ using the EC tracer method special issue of aerosol science and technology on findings from the fine particulate matter supersites program. Aerosol. Sci. Tech. 2004, 38, 140-155. [CrossRef] 
29. Strader, R.; Lurmann, F.; Pandis, S.N. Evaluation of secondary organic aerosol formation in winter. Atmos. Environ. 1999, 33, 4849-4863. [CrossRef]

30. Lim, H.J.; Turpin, B.J. Origins of primary and secondary organic aerosol in Atlanta: Results of time-resolved measurements during the Atlanta supersite experiment. Environ. Sci. Technol. 2002, 36, 4489-4496. [CrossRef] [PubMed]

31. Zhou, Y.; Xue, L.; Wang, T.; Gao, X.; Wang, Z.; Wang, X.; Zhang, J.; Zhang, Q.; Wang, W. Characterization of aerosol acidity at a high mountain site in central eastern China. Atmos. Environ. 2012, 51, 11-20. [CrossRef]

32. Wang, Z.; Wang, T.; Guo, J.; Gao, R.; Xue, L.; Zhang, J.; Zhou, Y.; Zhou, X.; Zhang, Q.; Wang, W. Formation of secondary organic carbon and cloud impact on carbonaceous aerosols at Mount Tai, North China. Atmos. Environ. 2012, 46, 516-527. [CrossRef]

33. Gillies, J.A.; Gertler, A.W. Comparison and evaluation of chemically speciated mobile source $\mathrm{PM}_{2.5}$ particulate matter profiles. J. Air. Waste Manag. 2000, 50, 1459-1480. [CrossRef]

34. Gillies, J.; Gertler, A.; Sagebiel, J.; Dippel, N.W. On-road particulate matter $\left(\mathrm{PM}_{2.5}\right.$ and $\left.\mathrm{PM}_{10}\right)$ emissions in the Sepulveda Tunnel, Los Angeles, California. Environ. Sci. Technol. 2001, 35, 1054-1063. [CrossRef] [PubMed]

35. Ram, K.; Sarin, M.M.; Hegde, P. Atmospheric abundances of primary and secondary carbonaceous species at two high-altitude sites in India: Sources and temporal variability. Atmos. Environ. 2008, 42, 6785-6796. [CrossRef]

36. Sudheer, A.; Sarin, M. Carbonaceous aerosols in MABL of Bay of Bengal: influence of continental outflow. Atmos. Environ. 2008, 42, 4089-4100. [CrossRef]

37. Chow, J.C.; Watson, J.G.; Kuhns, H.; Etyemezian, V.; Lowenthal, D.H.; Crow, D.; Kohl, S.D.; Engelbrecht, J.P.; Green, M.C. Source profiles for industrial, mobile, and area sources in the Big Bend Regional Aerosol Visibility and Observational study. Chemosphere 2004, 54, 185-208. [CrossRef] [PubMed]

38. Zhou, J.; Wang, Y.; Yue, T.; Li, Y.; Wai, K.M.; Wang, W. Origin and distribution of trace elements in high-elevation precipitation in southern China. Environ. Sci. Pollut. R. 2012, 19, 3389-3399. [CrossRef] [PubMed]

(C) 2016 by the authors; licensee MDPI, Basel, Switzerland. This article is an open access article distributed under the terms and conditions of the Creative Commons Attribution (CC-BY) license (http:/ / creativecommons.org/licenses/by/4.0/). 